\title{
Assessment of worldwide COVID-19 transmission landscape for predicting its upcoming severity along with a clinical update for its prevention
}

\author{
Adhyeta Choudhuri ${ }^{1}$, Maskura Khatun ${ }^{1}$, Arnab Bandyopadhyay ${ }^{1}$, Udayan Dasgupta ${ }^{1}$, \\ Sufia Chowdhury ${ }^{1}$, Anirban Biswas ${ }^{1}$, Indrani Samanta ${ }^{1}$, Dipanjana Das ${ }^{1}$, Debolina Sinha ${ }^{1}$, \\ Anantaa Ghatak ${ }^{1}$, Rima Das ${ }^{1}$, Sankar Ghosh ${ }^{1}$, Chinmay Saha ${ }^{1}$, and Sharbadeb Kundu ${ }^{1}$ \\ ${ }^{1}$ University of Kalyani
}

October 23, 2020

\begin{abstract}
The recent COVID-19 pandemic has created havoc across the globe. Although there are several controversies regarding its origin, the worldwide scientific fraternity currently indulges in developing various therapeutic strategies to combat this threat. Consequently, we aimed to provide a comprehensive evaluation of this pandemic's global transmission landscape to get an insight into its imminent fate on global populations. For this, we have analyzed the data on daily reported COVID-19 cases for 294 days since inception, i.e., from 31 December 2019 to 19 October 2020, in 210 countries across the five continents available in the ECDC database. Additionally, we have summarised an up-to-date list of currently available/under trial 23 drugs and vaccines to provide a consolidated reference to those who have a growing interest in knowing the status of related repurposed drugs and vaccines and to become acquainted with their mechanism of actions for preventing the pathogenesis of SARS-CoV-2 into the human host. We performed an extensive literature review to justify our findings and get the latest know-how on the COVID-19 pathogenesis. Our findings show that India is presently in the most critical condition, where the maximum COVID-19 cases (19.37\%) are reported globally in the last 14 days, which has turned into a major concern. So the government should give priority to deal with this pandemic. Besides, American and European countries are also in a risky position, as they harbor $33.31 \%$ and $34.52 \%$ of total COVID-19 cases in the last 14 days, respectively. The sudden spurt in the number of COVID-19 cases in Europe due to the beginning of extensive testing probably reflects the relaxation in policies for controlling this pandemic. Nevertheless, we should make predictions on how this virus would evolve further, which might help us design a 'magic compound' that can prevent any likely situation.
\end{abstract}

\section{Hosted file}

TBED_COVID-paper_2020_230ct.pdf available at https://authorea.com/users/369763/articles/ 488567-assessment-of-worldwide-covid-19-transmission-landscape-for-predicting-itsupcoming-severity-along-with-a-clinical-update-for-its-prevention 


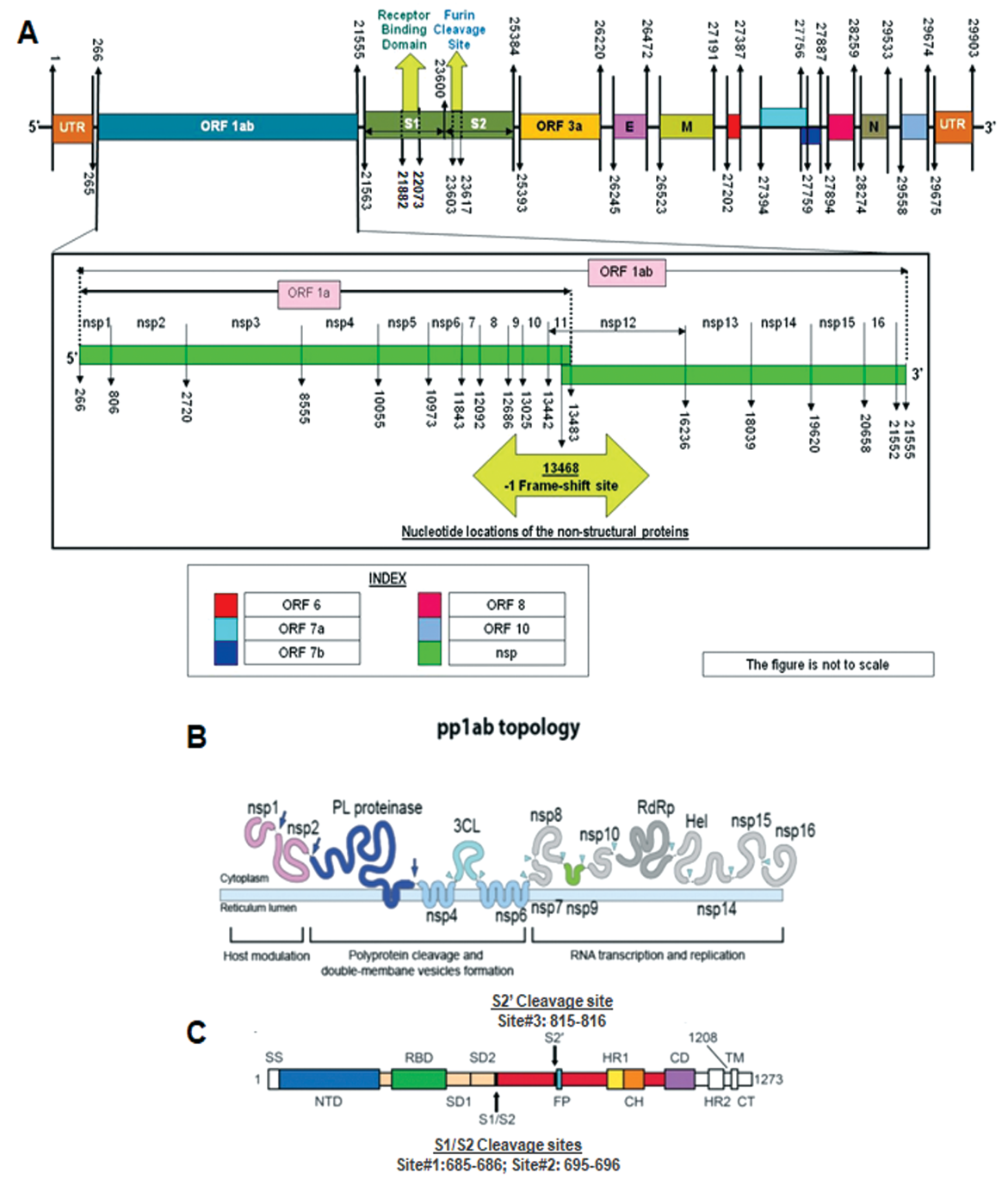


A
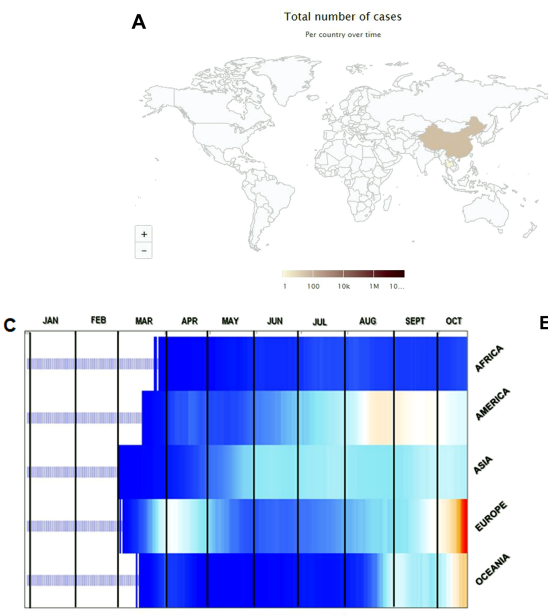

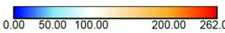

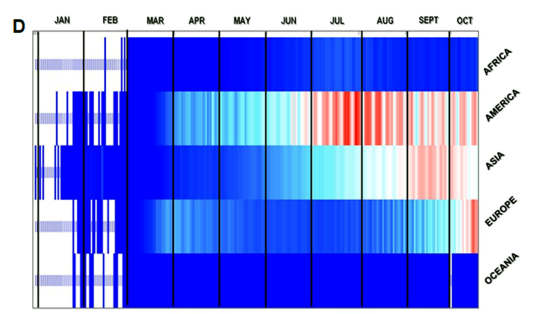

$0.00 \quad 50000.00 \quad 1000000.00 \quad 183371.00$
B Total number of cases
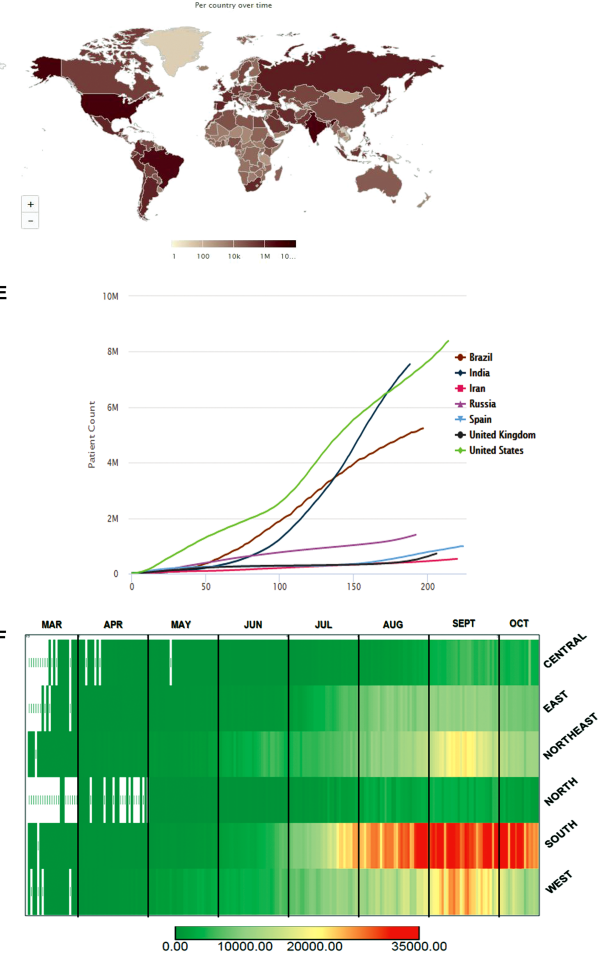

\begin{tabular}{|l|l} 
SARS-CoV-2 \\
\hline $\begin{array}{c}\text { Umifenovir } \\
\text { Nafamostat mesylate } \\
\text { Bromhexine } \\
\text { prevent viral entry }\end{array}$ \\
\hline $\begin{array}{c}\text { Inhibits membrane fusion } \\
\text { to the viral envelop }\end{array}$ \\
\hline
\end{tabular}
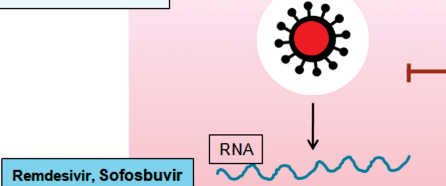

Remdesivir, Sofosbuvir
Ribavirin, Galidesivir

Ravipiravir
Favinition Replication

Chaintermination by 败

Ritonavir-Lopinavir

Chain termination by 